\title{
Regioselective Synthesis of Substituted 4-Alkylamino
}

\section{and 4-Arylaminophthalazin-1(2H)-ones}

\author{
Subramaniam Krishnananthan*a, Daniel Smith ${ }^{\mathrm{a}}$, Dauh-Rurng Wu ${ }^{\mathrm{a}}$, Shiuhang Yip ${ }^{\mathrm{a}}$, Prashantha Gunaga ${ }^{\mathrm{b}}$, \\ Arvind Mathur ${ }^{\mathrm{a}}$ and Jianqing $\mathrm{Li}^{*^{\mathrm{a}}}$ \\ Discovery Chemistry, Research and Development, Bristol-Myers Squibb Company, ${ }^{a}$ PO Box \\ 4000, Princeton, NJ 08543-4000, ${ }^{b}$ Biocon Bristol-Myers Squibb R\&D Center, Biocon Park, \\ Bommasandra IV phase, Jigani Link Road, Bangalore - 560099, India
}

Krishnananthan, Subramaniam@,bms.com and Jianqing.Li@bms.com

\section{SUPPORTING INFORMATION}

\section{Table of Contents}

1. NMR spectra of compound 3a

Page S3

2. NMR spectra of compound $\mathbf{3 b}$

Page S4

3. NMR spectra of compound 3c

Page S5

4. NMR spectra of compound $\mathbf{3 e}$

Page S6

5. NMR spectra of compound $\mathbf{3 f}$

Page S7

6. NMR spectra of compound $4 \mathbf{a}$

Page S8

7. NMR spectra of compound $\mathbf{4 b}$

Page S9

8. NMR spectra of compound $\mathbf{4 c}$

Page S10

9. NMR spectra of compound $\mathbf{4 d}$

Page S11

10. NMR spectra of compound $4 \mathbf{e}$

Page S12

11. NMR spectra of compound $\mathbf{5 a}$

Page S13 
12. NMR spectra of compound $\mathbf{5 b}$

Page S14

13. NMR spectra of compound $\mathbf{5 c}$

Page S15

14. NMR spectra of compound $\mathbf{5 d}$

Page S16

15. NMR spectra of compound $\mathbf{5 e}$

Page S17

16. NMR spectra of compound $\mathbf{5 f}$

Page S18

17. NMR spectra of compound $\mathbf{5 g}$

Page S19

18. NMR spectra of compound $\mathbf{5 h}$

Page S20

19. NMR spectra of compound $\mathbf{5 i}$

Page S21

20. NMR spectra of compound $\mathbf{5 j}$

Page S22

21. NMR spectra of compound $\mathbf{5 k}$

Page S23

22. NMR spectra of compound $\mathbf{5 l}$

Page S24 
${ }^{1}$ H NMR and ${ }^{13} \mathrm{C}$ NMR spectra of 7-chlorophthalazin-1(2H)-one (3a)<smiles>O=c1[nH]ncc2ccc(Cl)cc12</smiles>
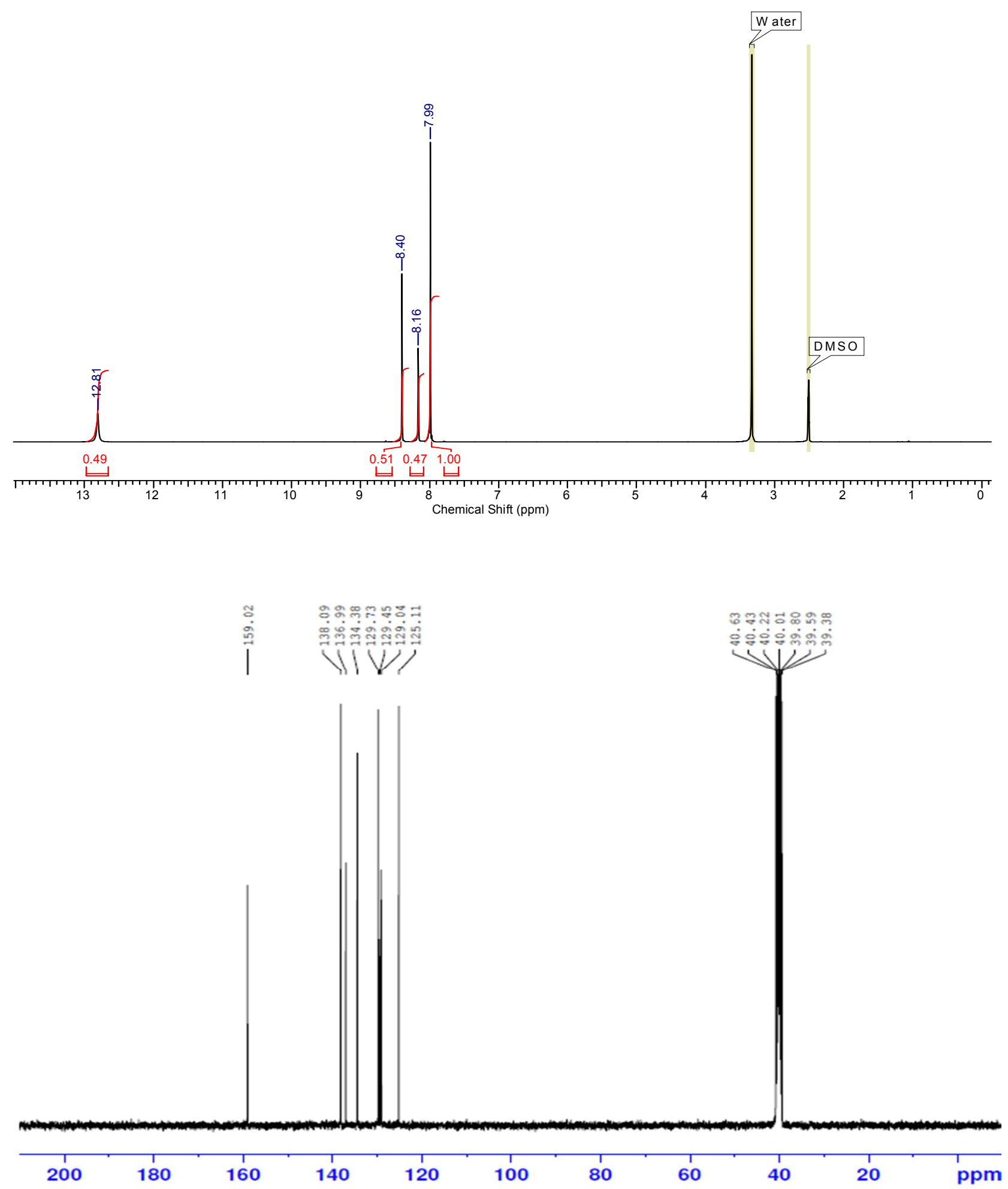
${ }^{1}$ H NMR and ${ }^{13} \mathrm{C}$ NMR spectra of 7,8-dimethoxyphthalazin-1(2H)-one (3b)<smiles>COc1ccc2cn[nH]c(=O)c2c1OC</smiles>
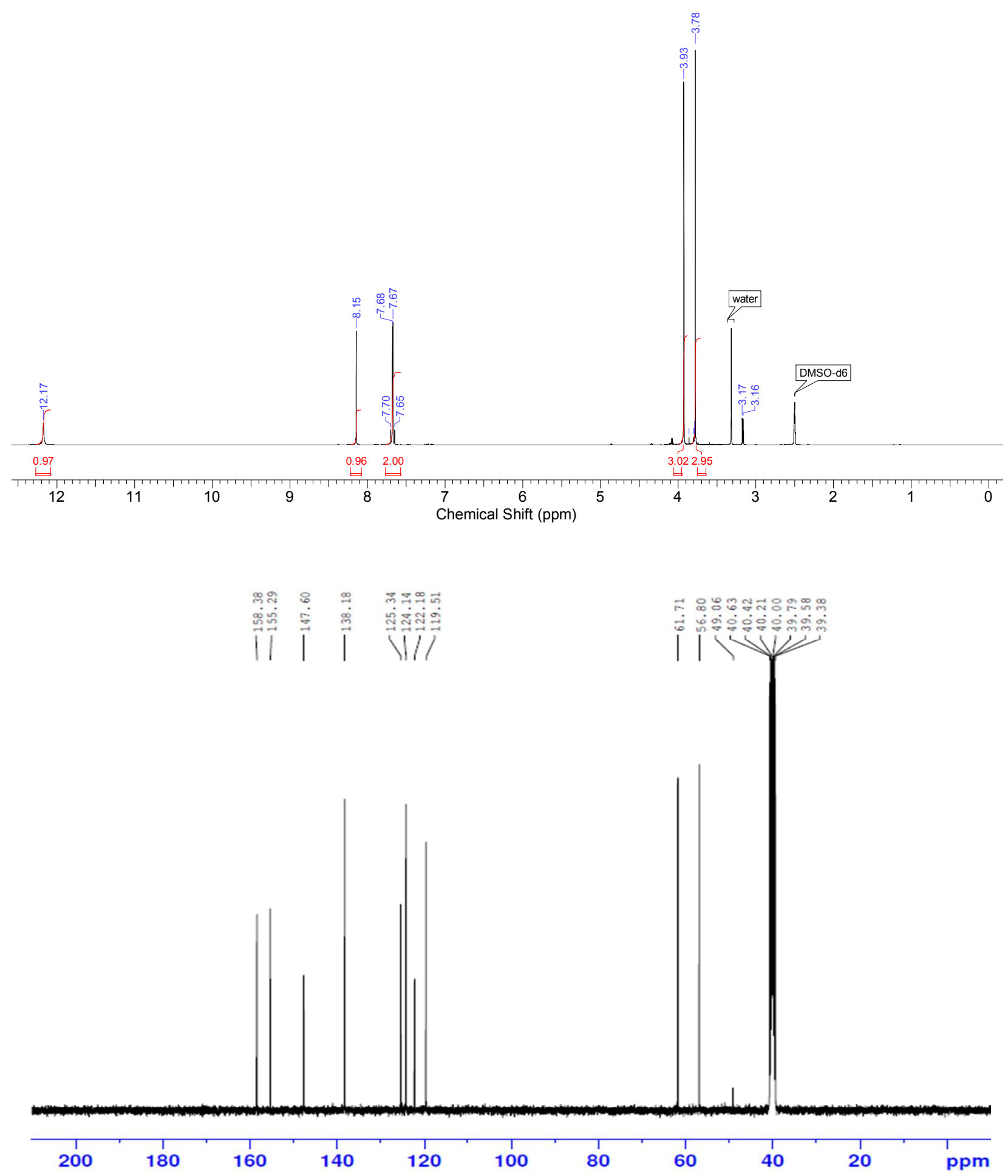
${ }^{1} \mathrm{H}$ NMR and ${ }^{13} \mathrm{C}$ NMR spectra of 7-methoxyphthalazin-1(2H)-one (3c)

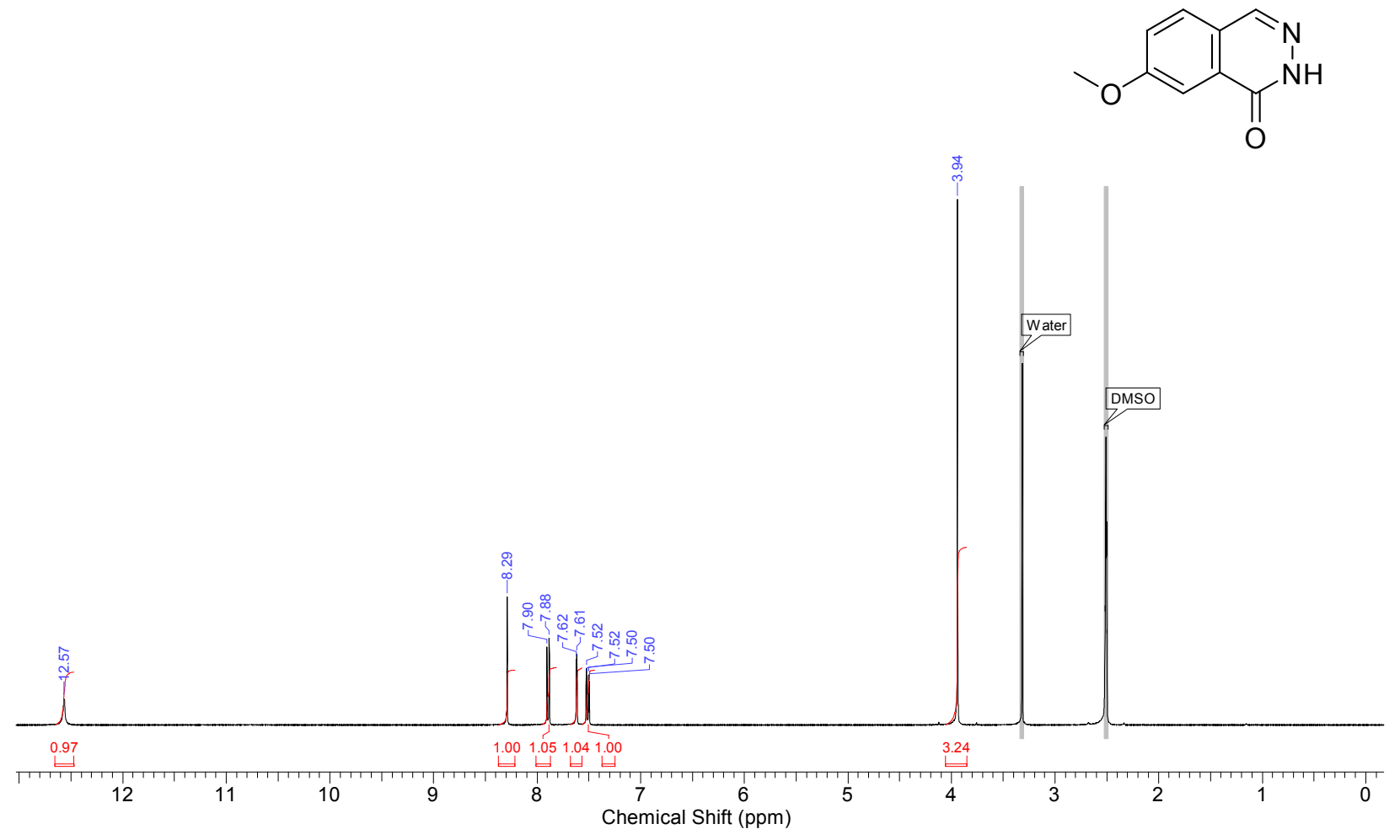

ๆิ छำฺำ

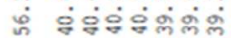

|

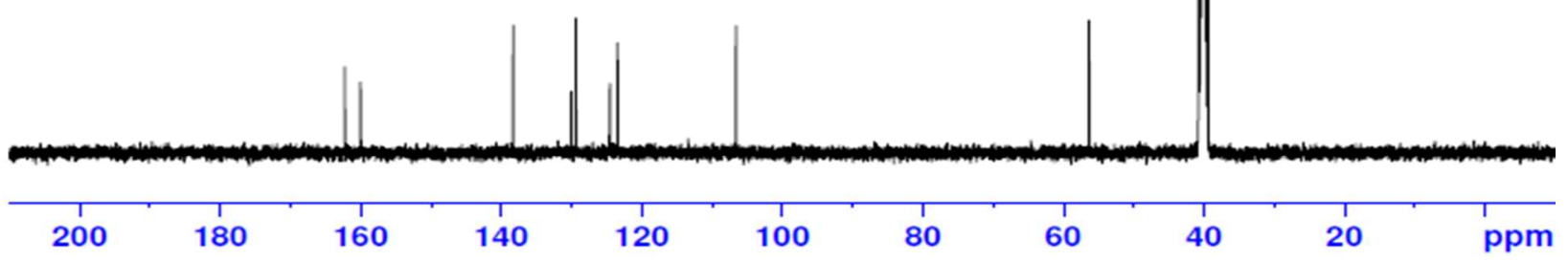


${ }^{1} \mathrm{H}$ NMR and ${ }^{13} \mathrm{C}$ NMR spectra of 5-bromophthalazin-1-ol (3e)
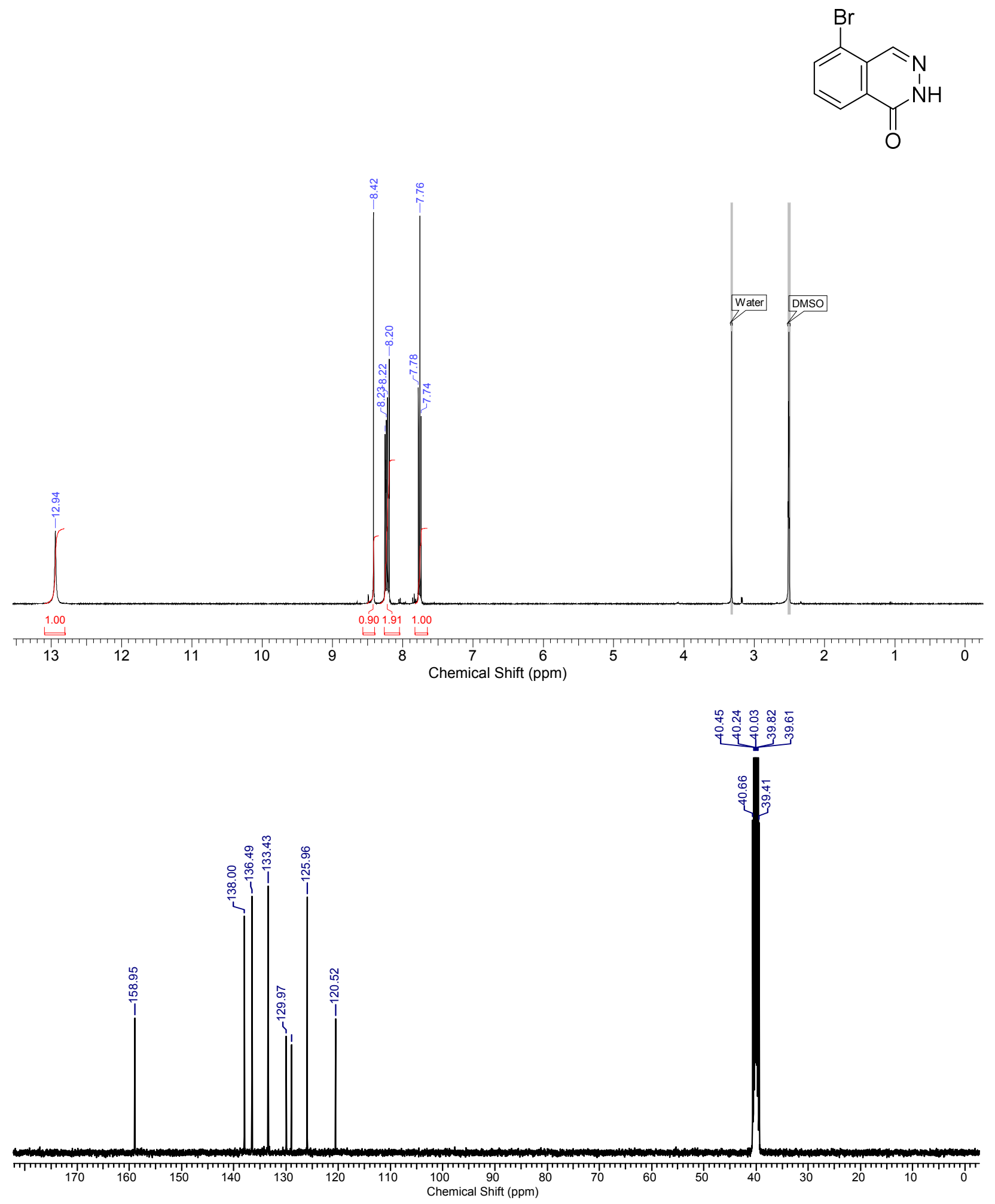
${ }^{1} \mathrm{H}$ NMR and ${ }^{13} \mathrm{C}$ NMR spectra of 5-phenylphthalazin-1(2H)-one (3f)

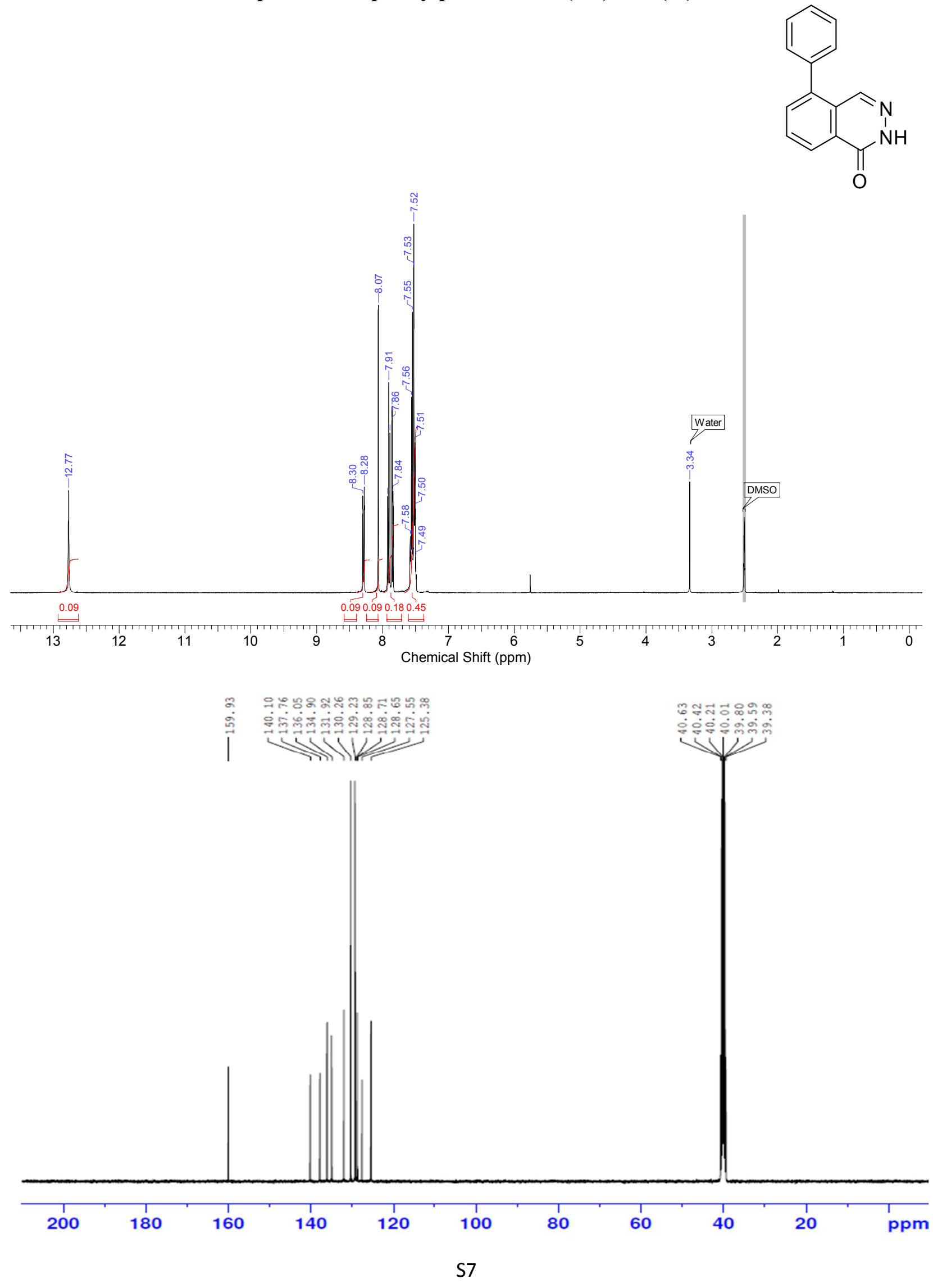


${ }^{1} \mathrm{H}$ NMR and ${ }^{13} \mathrm{C}$ NMR spectra of 4-bromo-7-chlorophthalazin-1(2H)-one (4a)

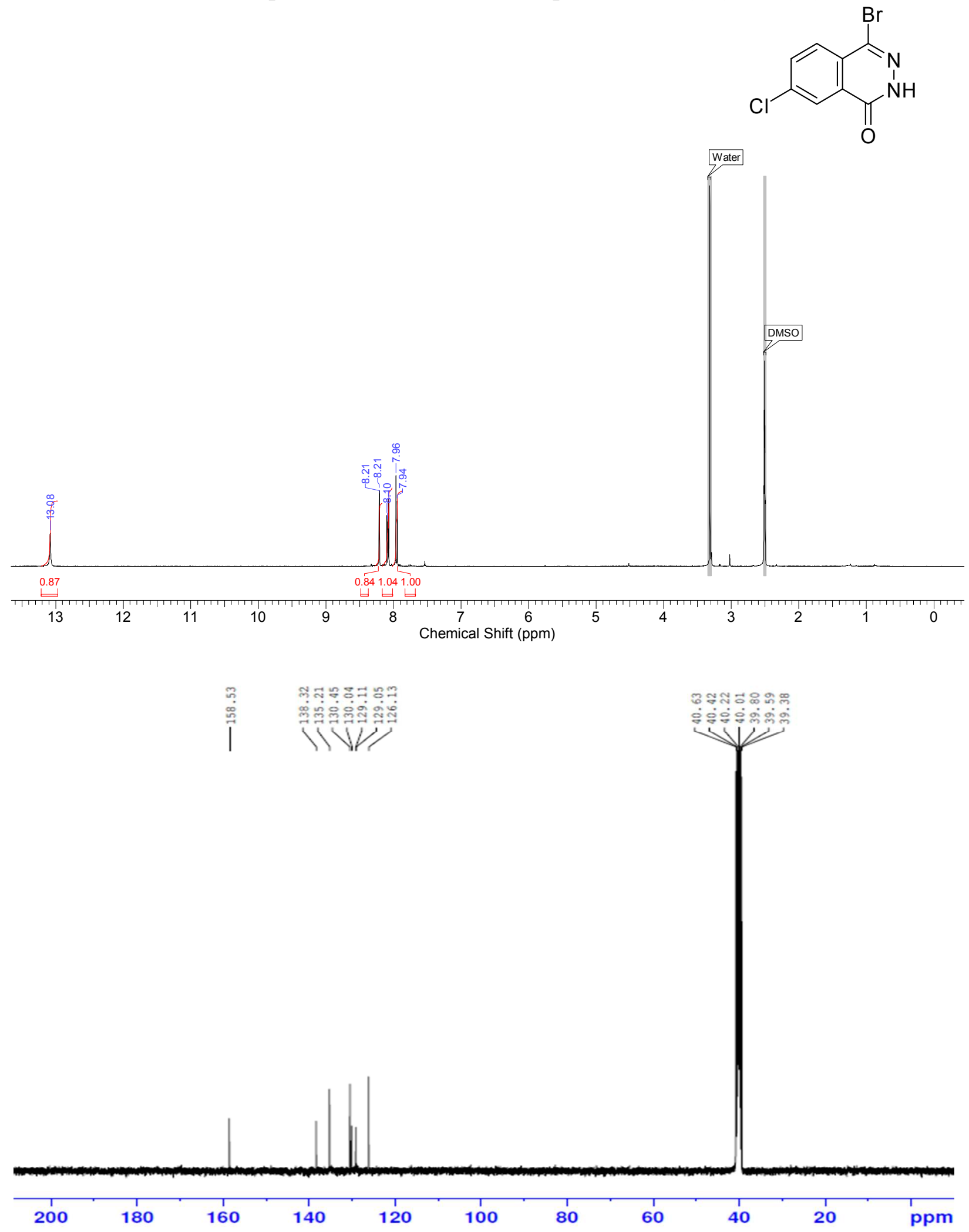




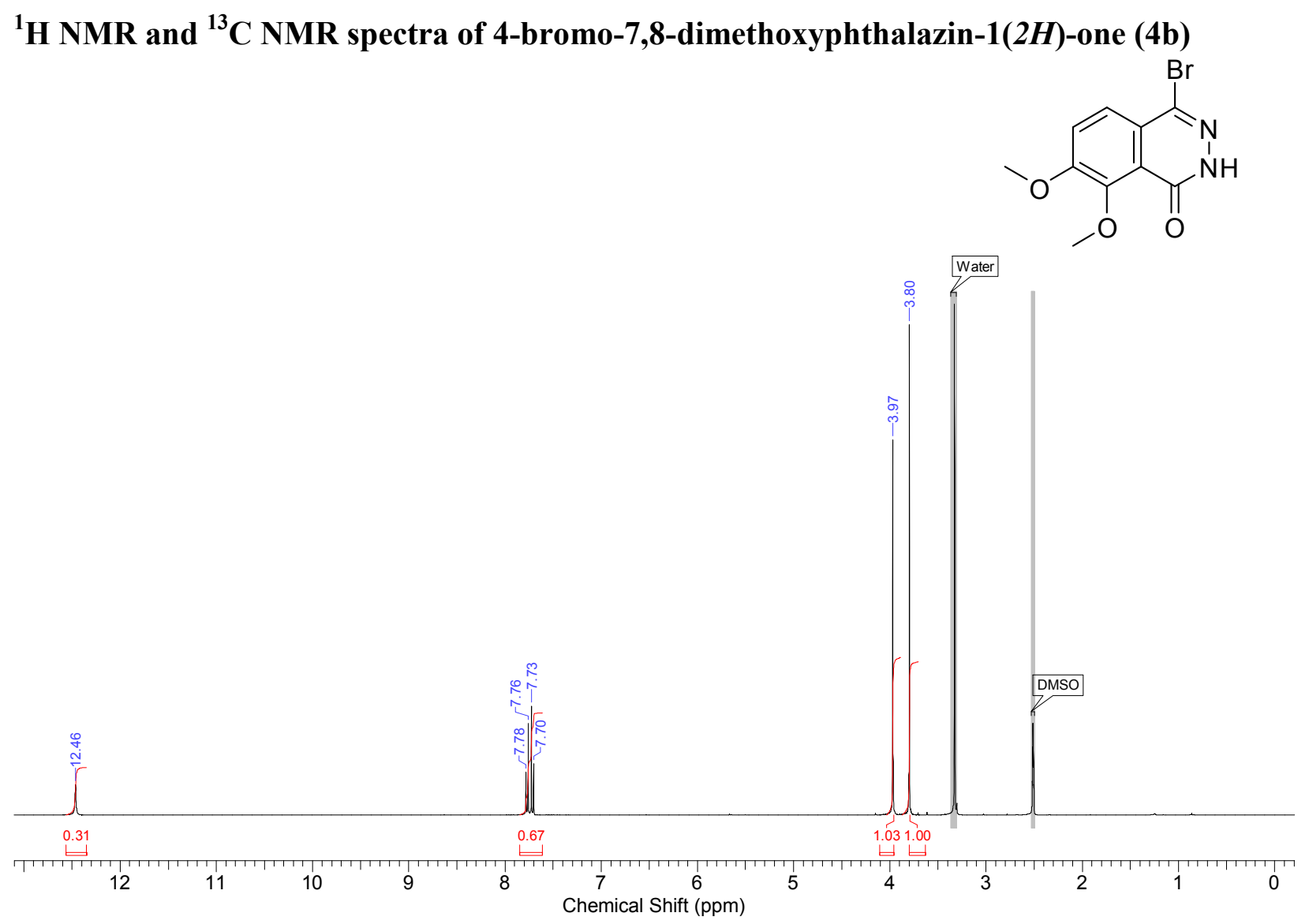

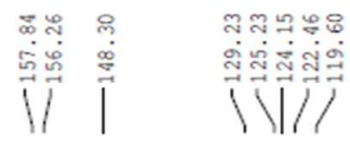
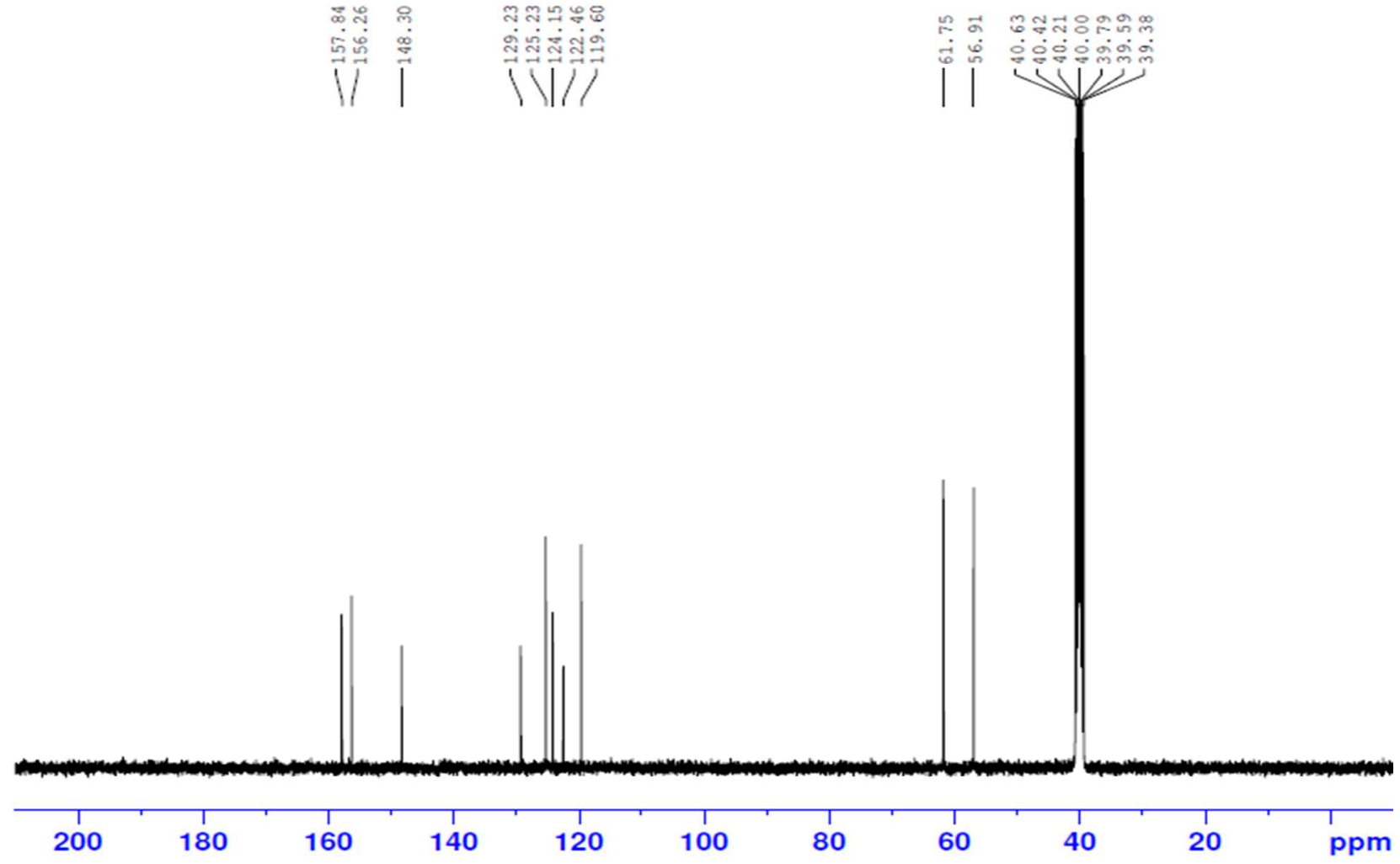

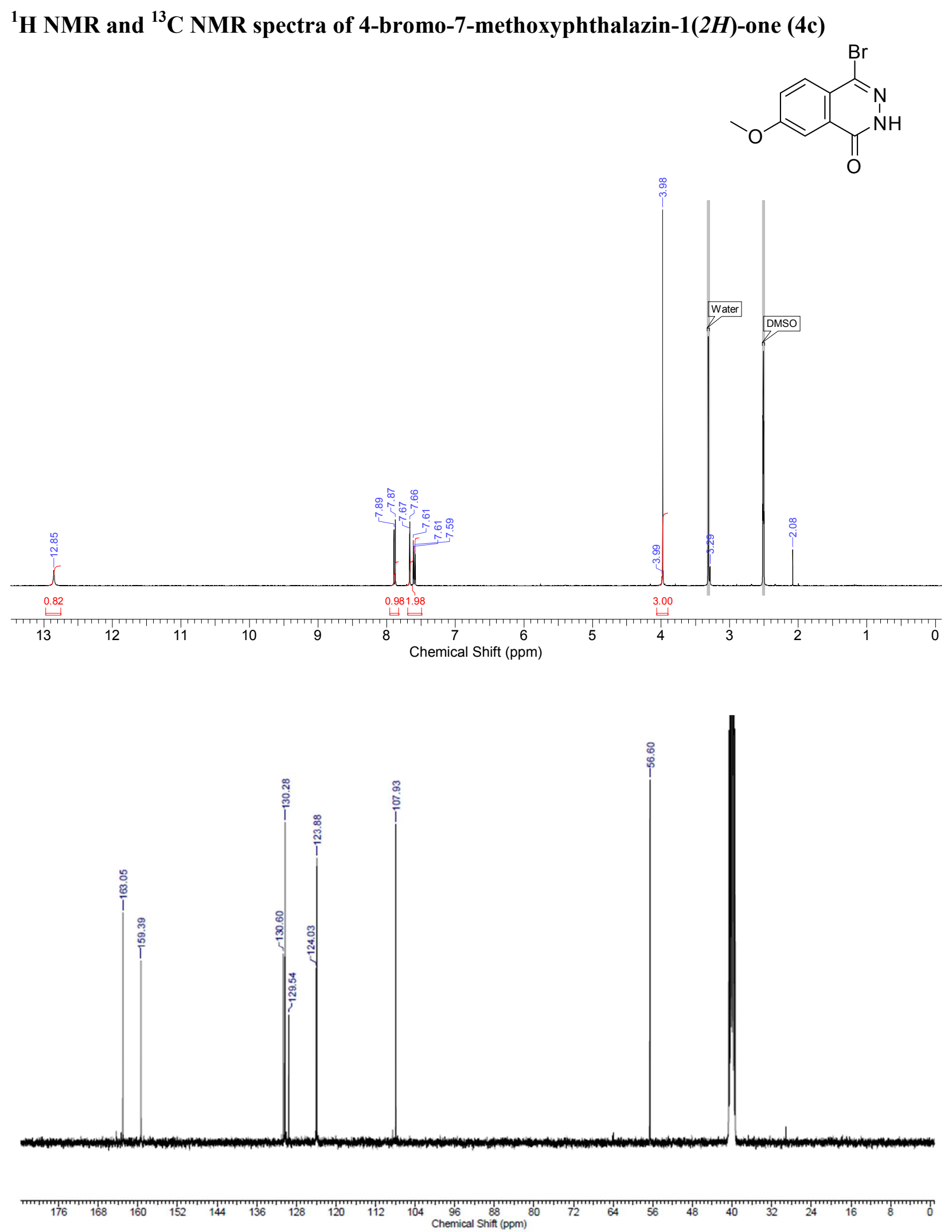
${ }^{1} \mathrm{H}$ NMR and ${ }^{13} \mathrm{C}$ NMR spectra of 4-bromophthalazin-1(2H)-one (4d)
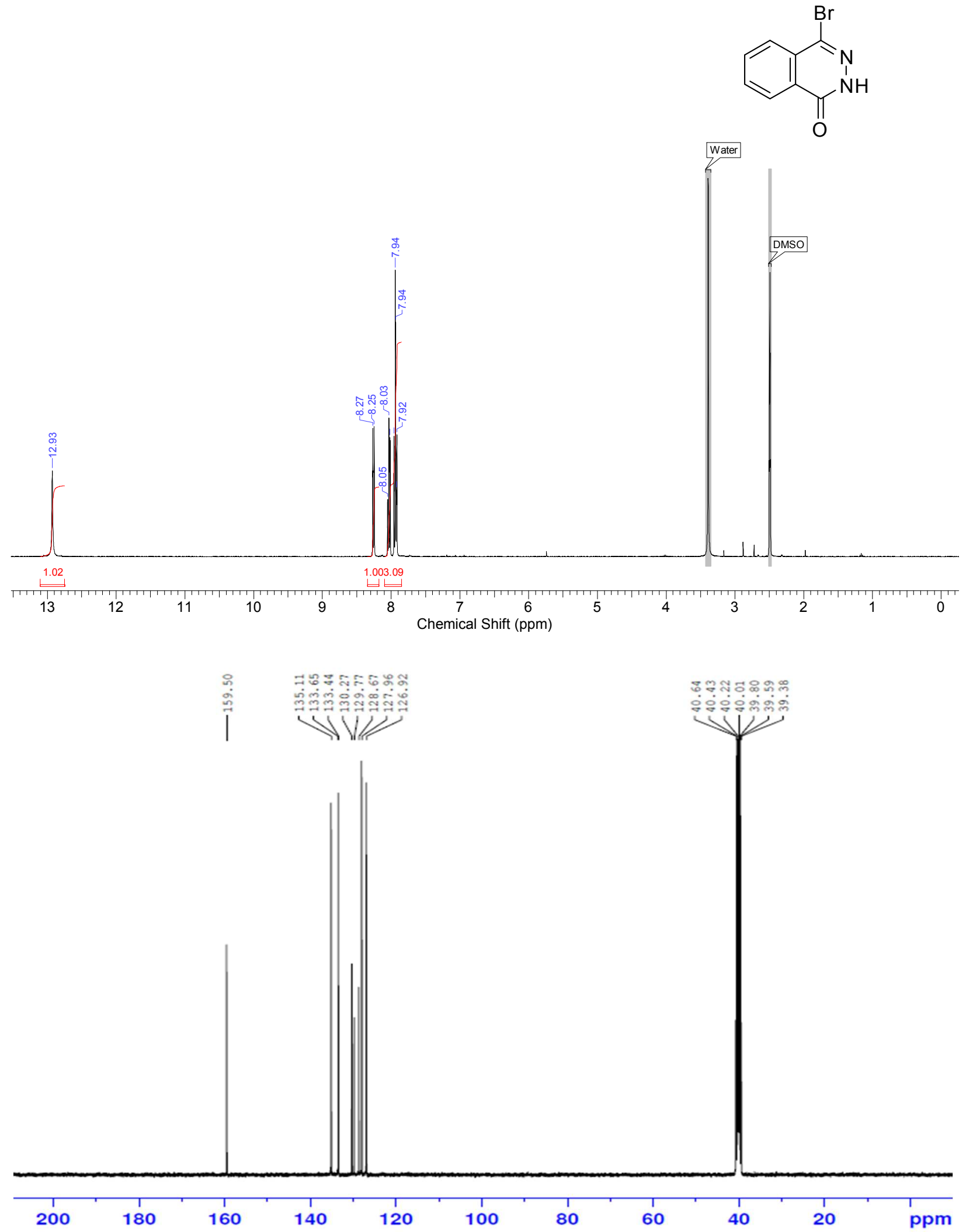
${ }^{1} \mathrm{H}$ NMR and ${ }^{13} \mathrm{C}$ NMR spectra of 4-bromo-5-phenylphthalazin-1(2H)-one (4e)
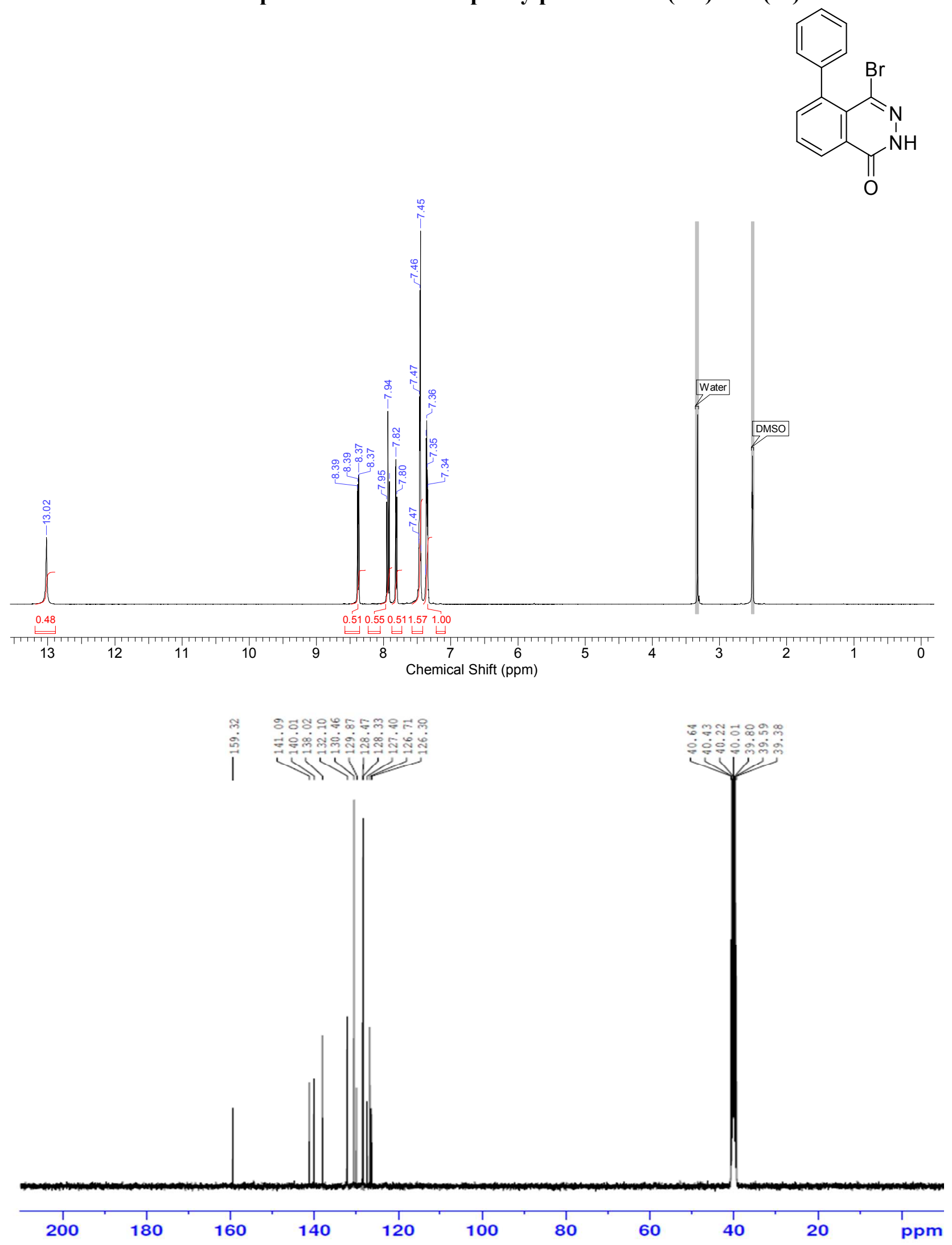
${ }^{1}$ H NMR and ${ }^{13} \mathrm{C}$ NMR spectra of 7-chloro-4-((3-hydroxypropyl)amino)phthalazin-1(2H)one (5a)

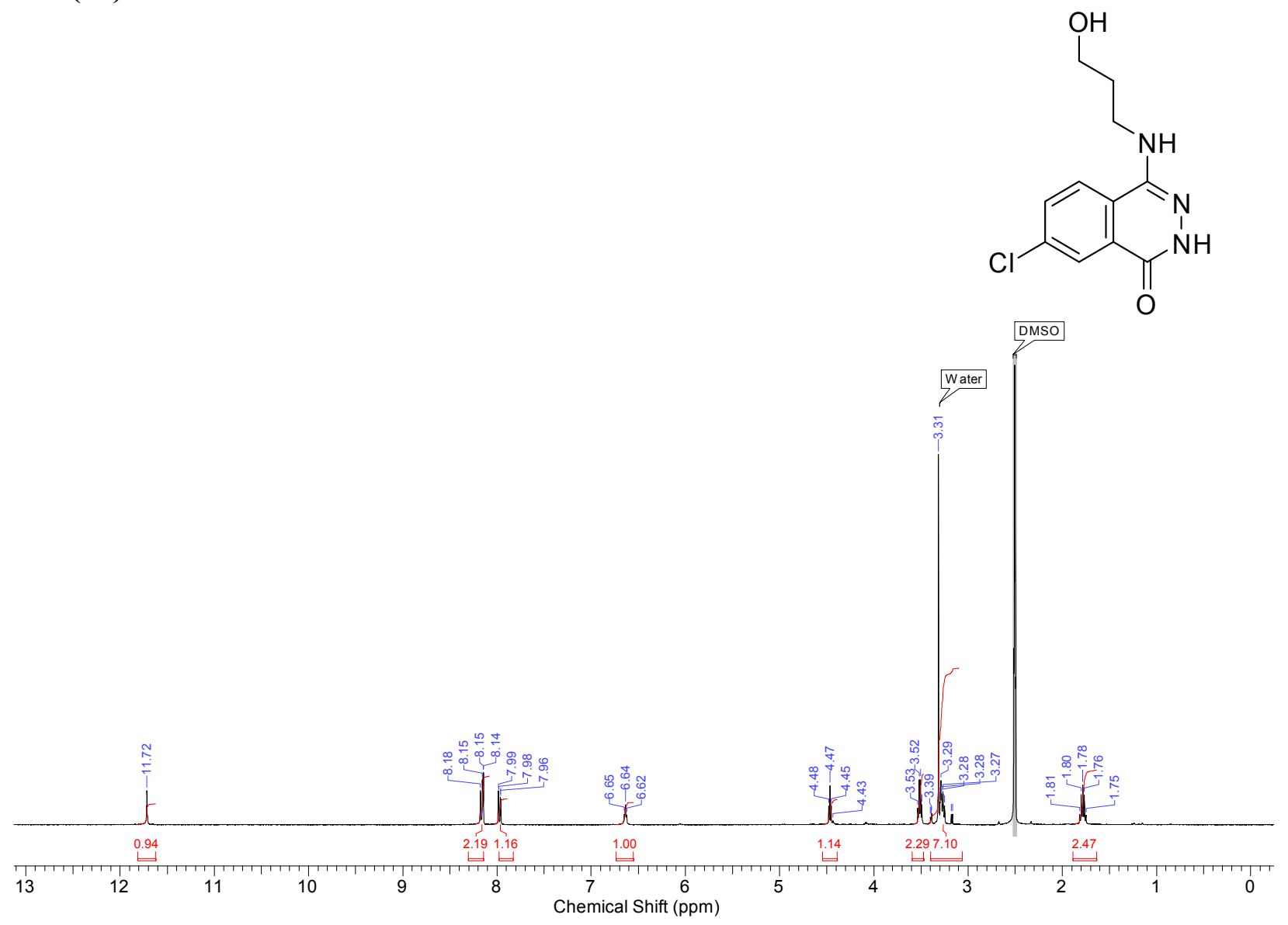

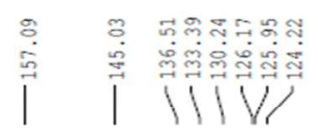

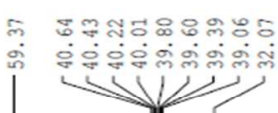$$
13
$$

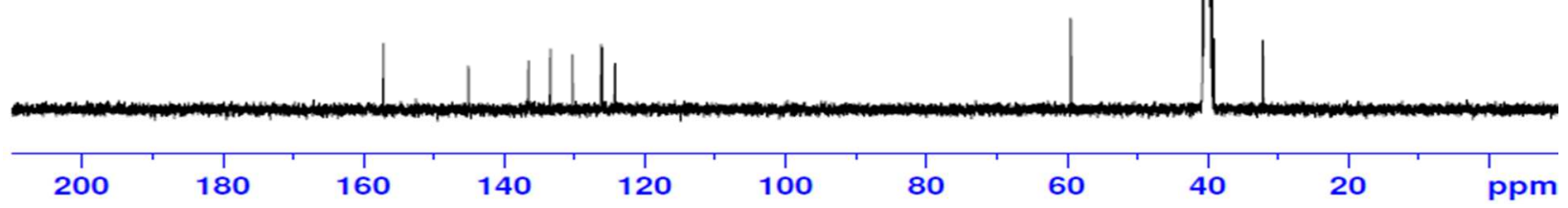


${ }^{1} \mathrm{H}$ NMR and ${ }^{13} \mathrm{C}$ NMR spectra of (R)-7-chloro-4-((1-hydroxypropan-2-yl)amino)phthalazin-1(2H)-one (5b)

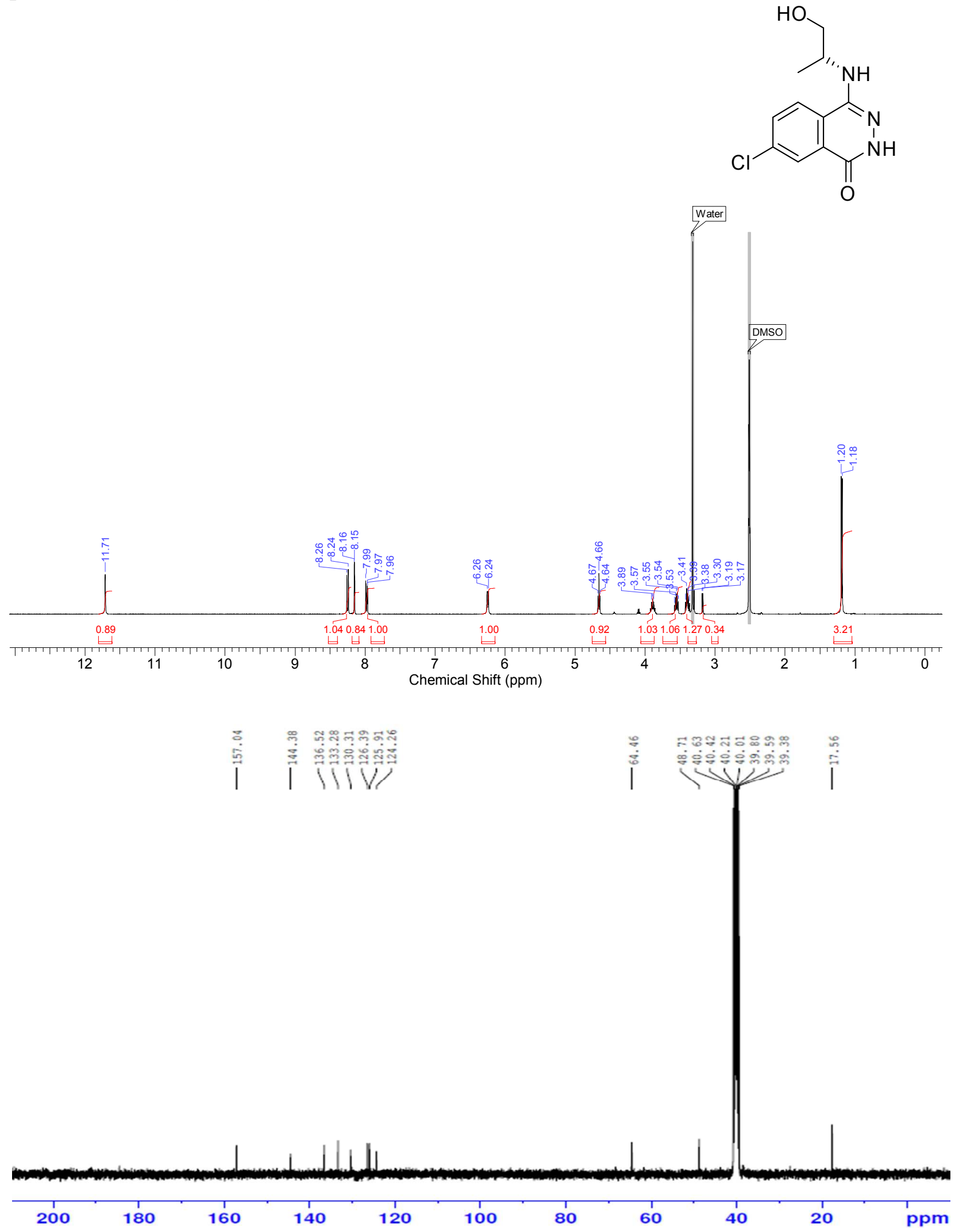


${ }^{1} \mathrm{H}$ NMR and ${ }^{13} \mathrm{C}$ NMR spectra of 3-((6-chloro-4-hydroxyphthalazin-1-yl)amino)propane1,2-diol (5c)

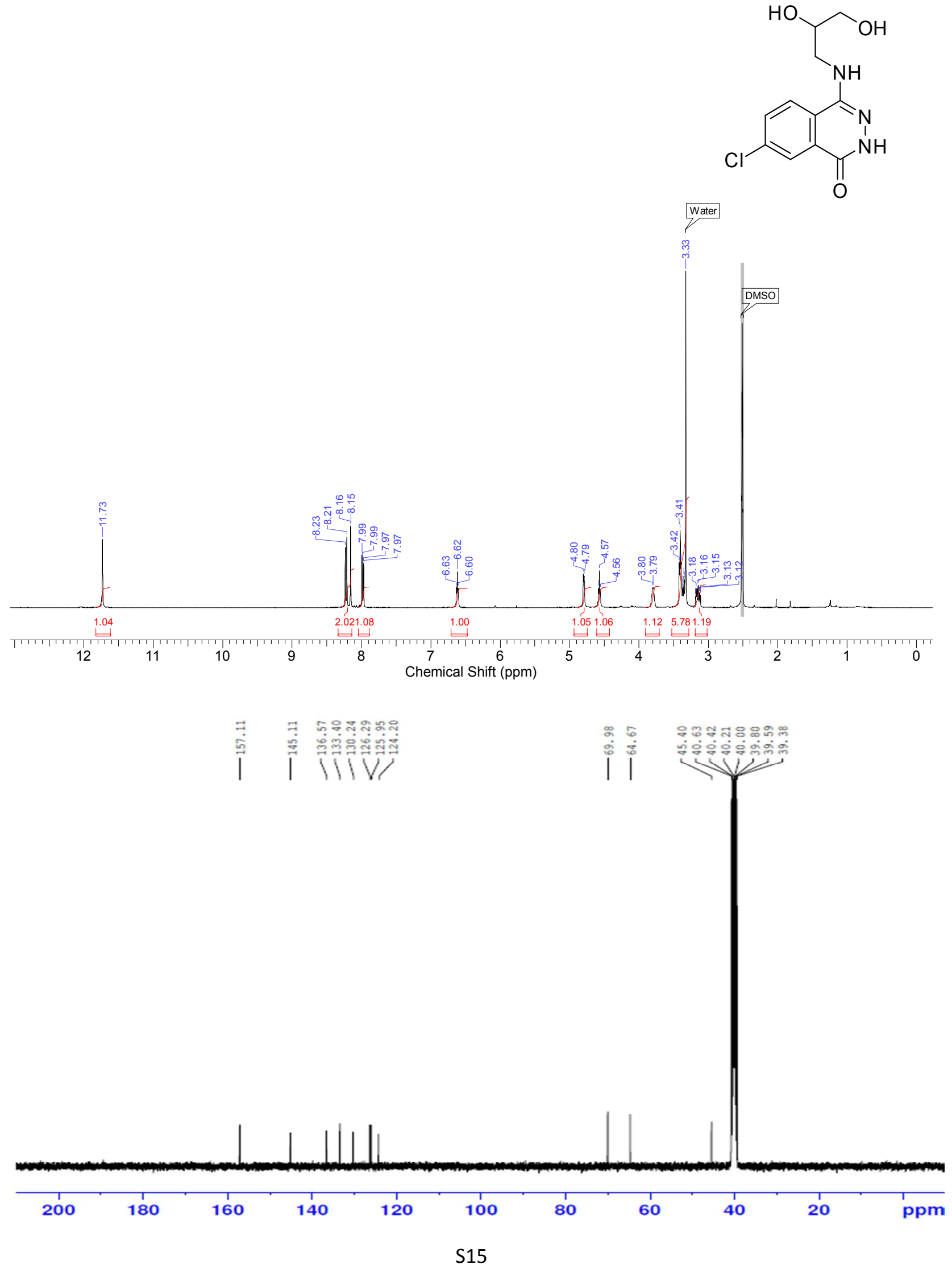


${ }^{1} \mathrm{H}$ NMR and ${ }^{13} \mathrm{C}$ NMR spectra of 4-(butylamino)-7,8-dimethoxyphthalazin-1(2H)-one (5d)

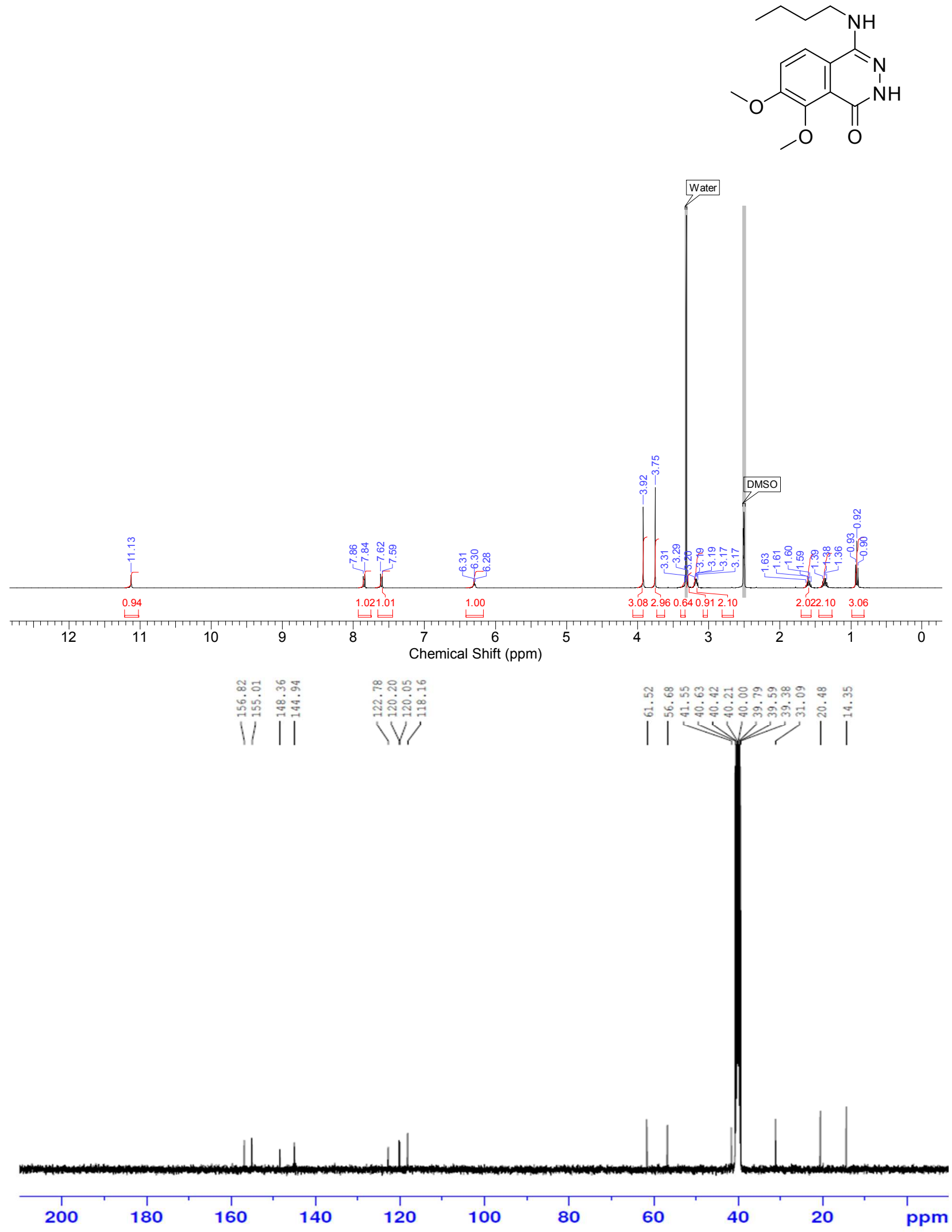


${ }^{1} \mathrm{H}$ NMR and ${ }^{13} \mathrm{C}$ NMR spectra of 4-((4-chlorophenyl)amino)-7-methoxyphthalazin-1(2H)one (5e)

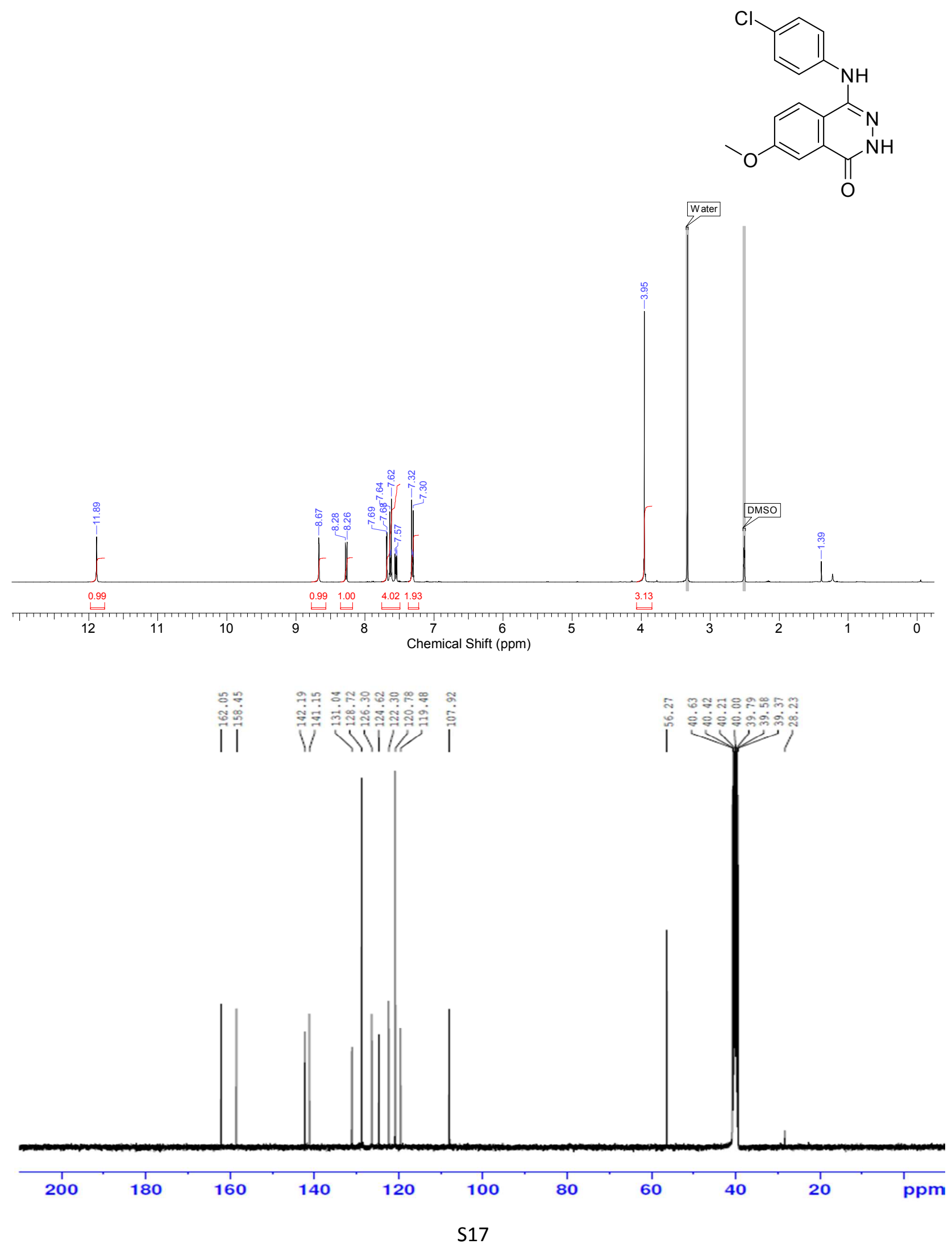


${ }^{1} \mathrm{H}$ NMR and ${ }^{13} \mathrm{C}$ NMR spectra of 7-methoxy-4-((4-methoxyphenyl)amino)phthalazin1(2H)-one (5f)
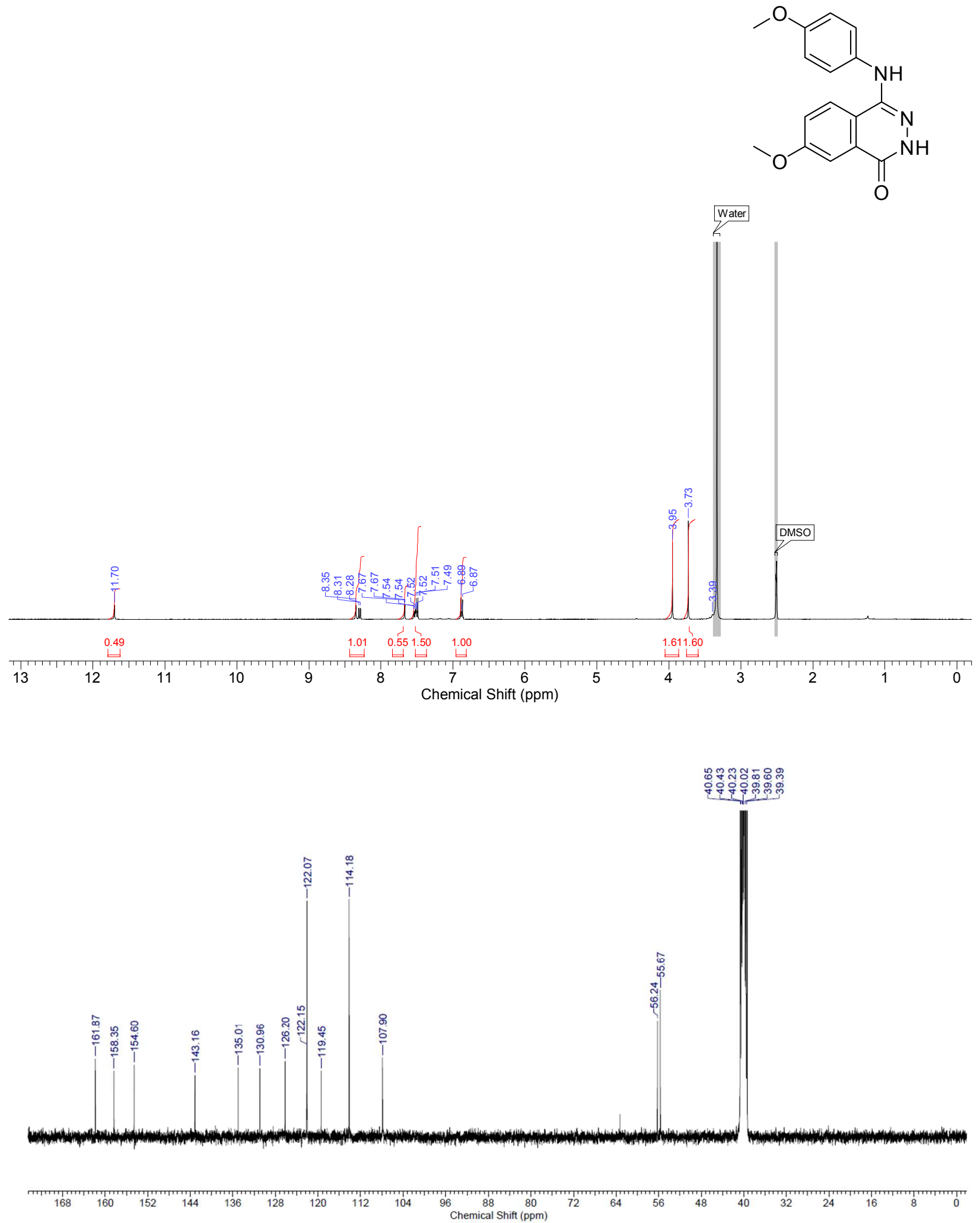
${ }^{1} \mathrm{H}$ NMR and ${ }^{13} \mathrm{C}$ NMR spectra of 4-(isopentylamino)phthalazin-1(2H)-one (5g)
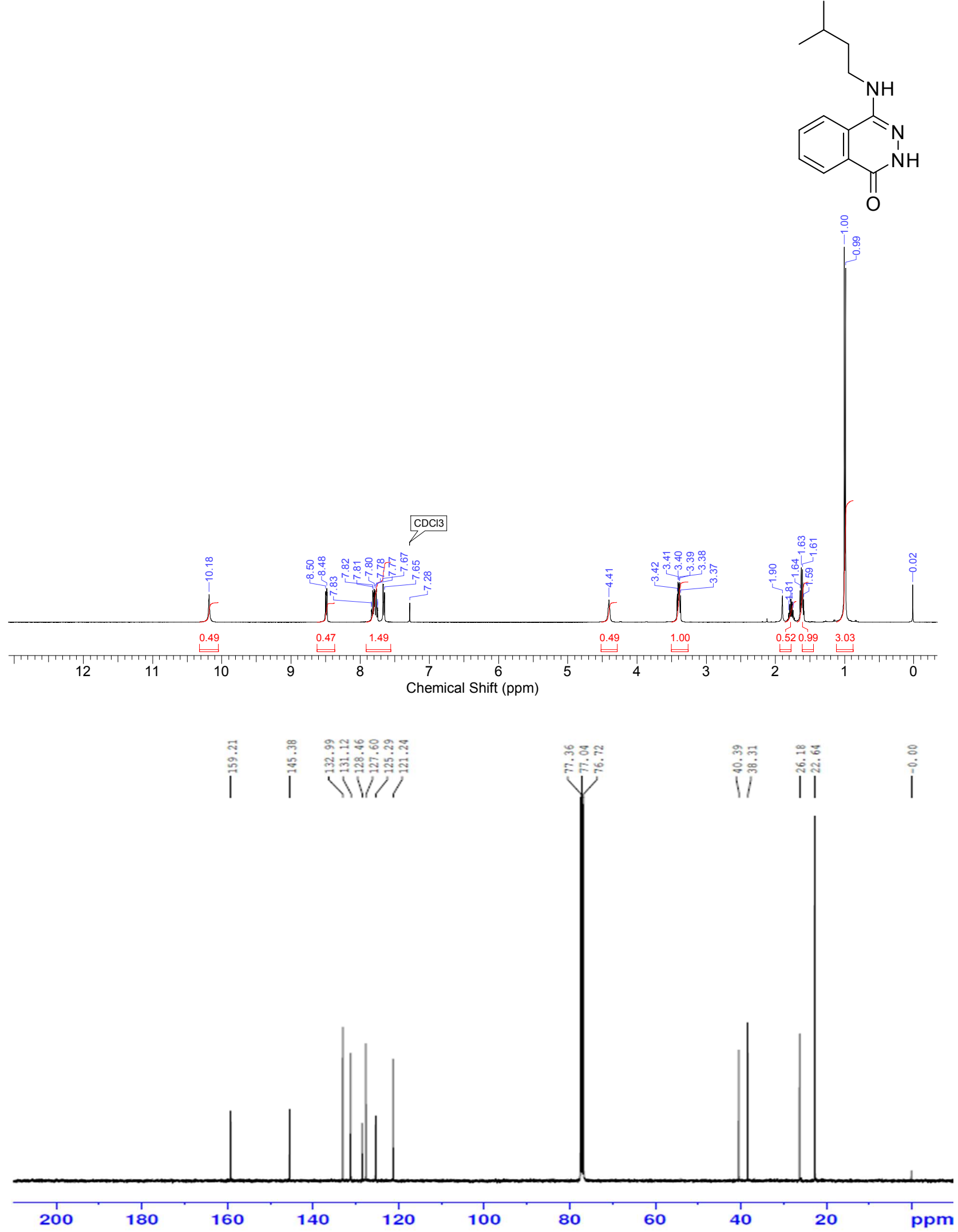
${ }^{1} \mathrm{H}$ NMR and ${ }^{13} \mathrm{C}$ NMR spectra of 4-(phenylamino)phthalazin-1(2H)-one (5h)
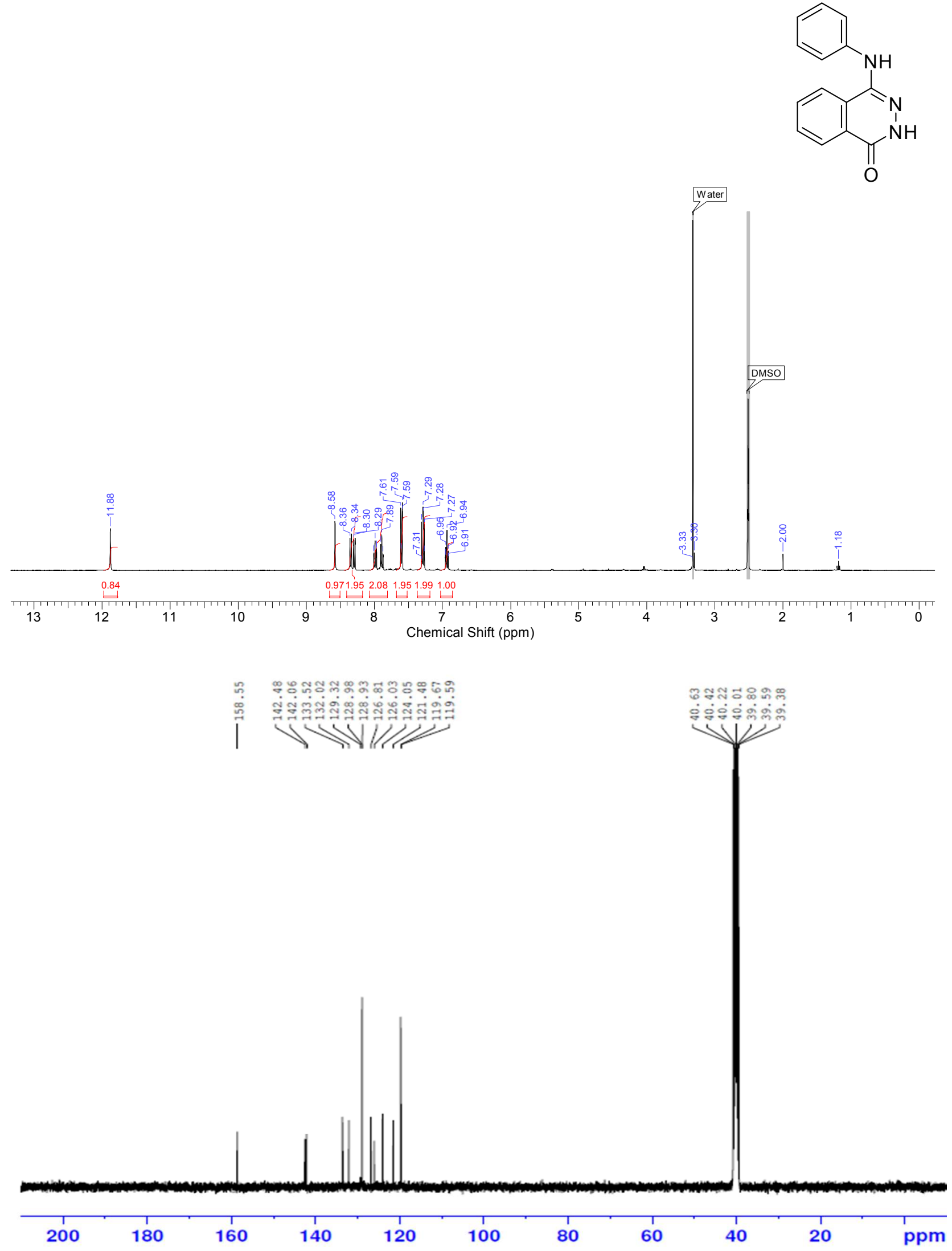
${ }^{1} \mathrm{H}$ NMR and ${ }^{13} \mathrm{C}$ NMR spectra of 4-((3-(dimethylamino)propyl)amino)phthalazin-1(2H)one (5i)
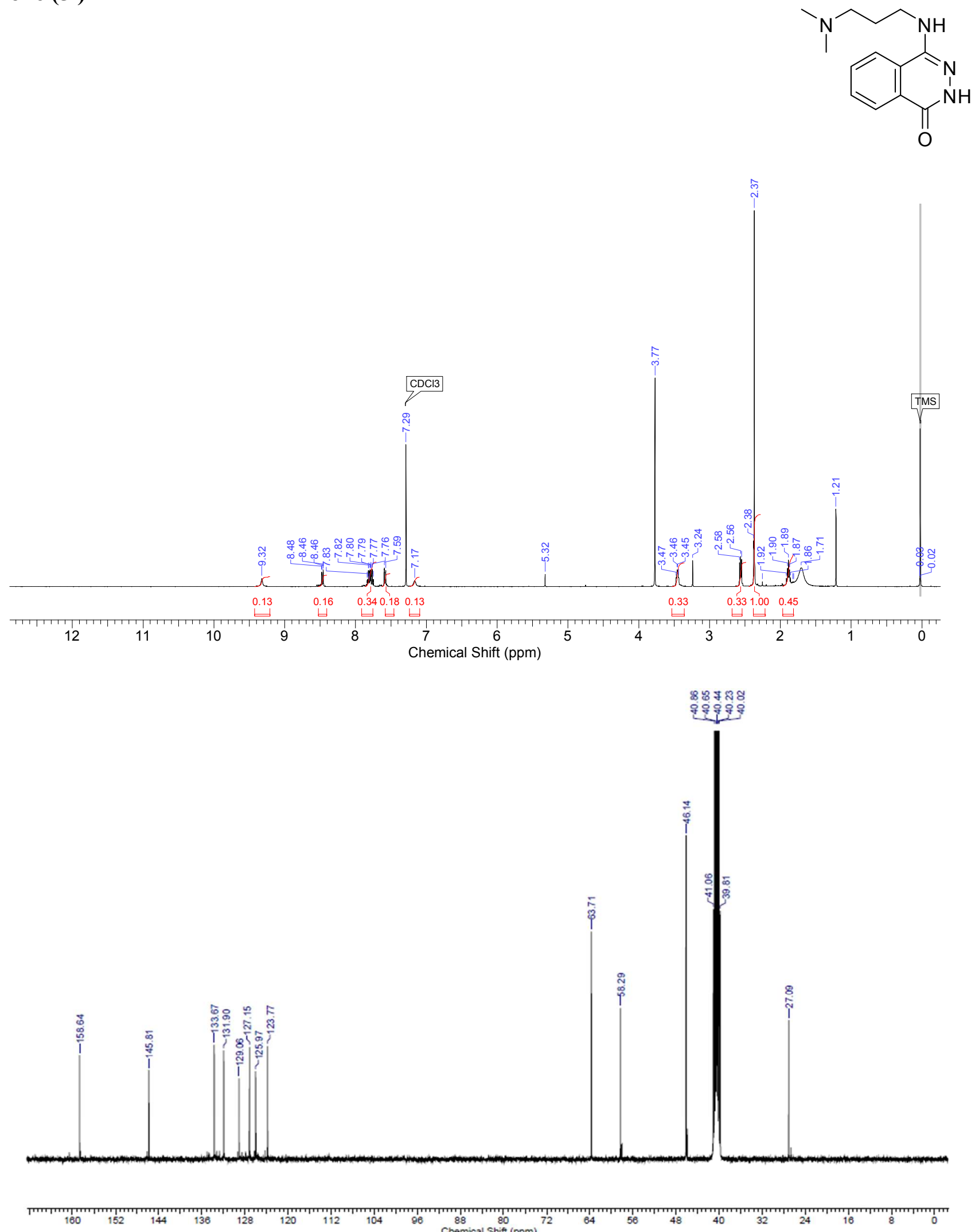
${ }^{1}$ H NMR and ${ }^{13}$ C NMR spectra of 3-((4-hydroxyphthalazin-1-yl)amino)-3-methylbutanoic acid (5j)

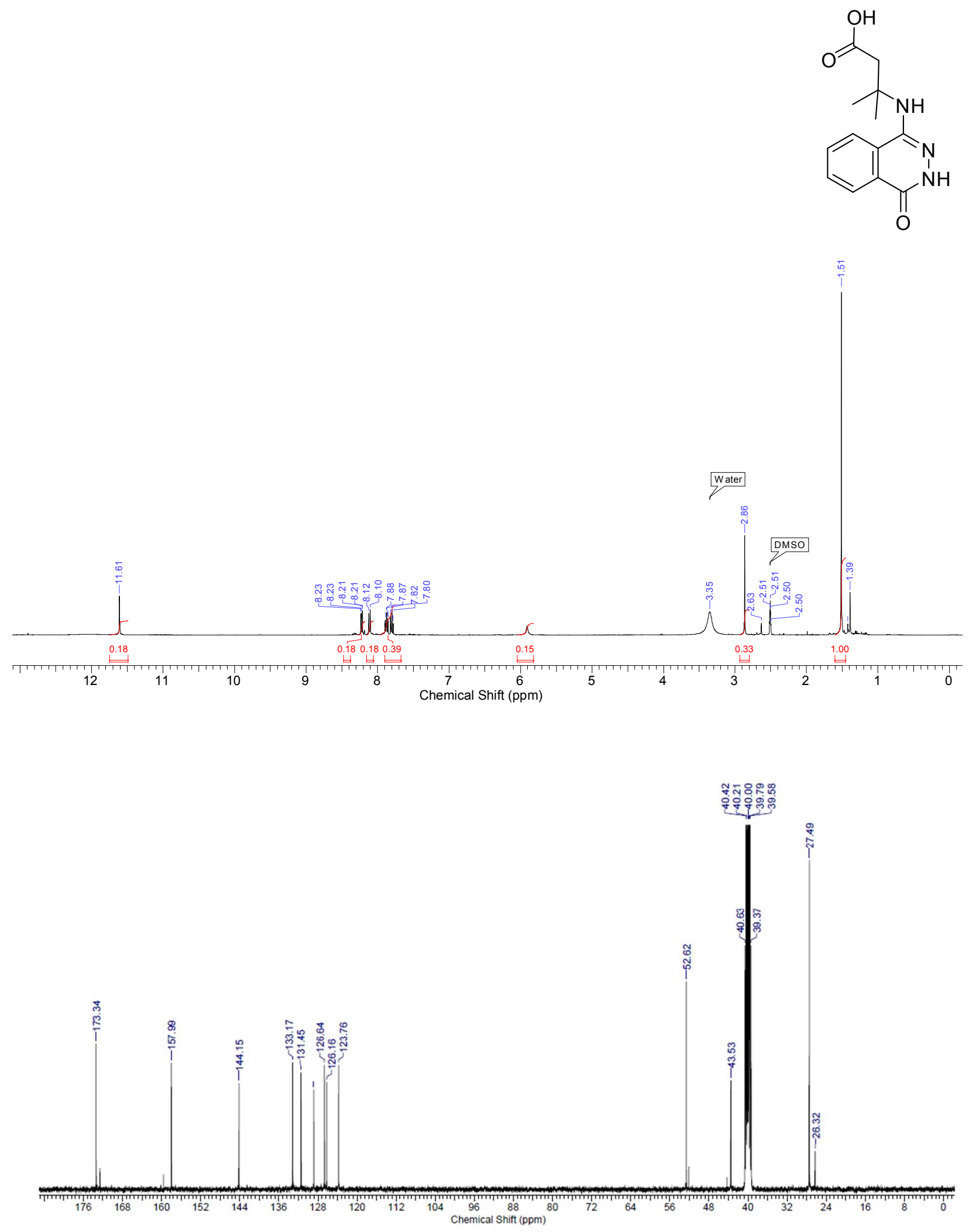


${ }^{1}$ H NMR and ${ }^{13} \mathrm{C}$ NMR spectra of 5-phenyl-4-((pyridin-2-ylmethyl)amino)phthalazin1(2H)-one (5k)

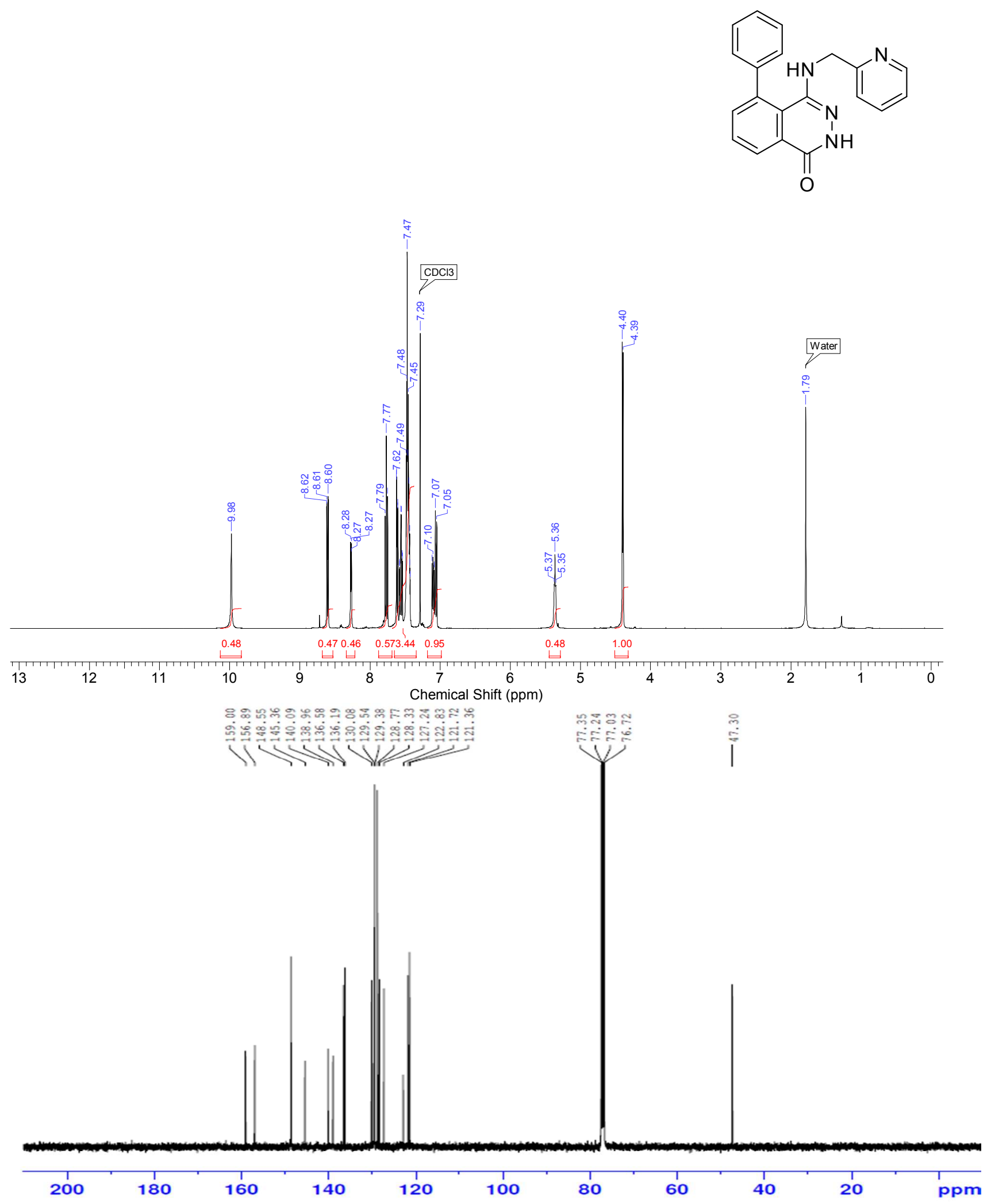


${ }^{1}$ H NMR and ${ }^{13}$ C NMR spectra of 4-((2-hydroxyethyl)amino)-5-phenylphthalazin-1(2H)one (5l)

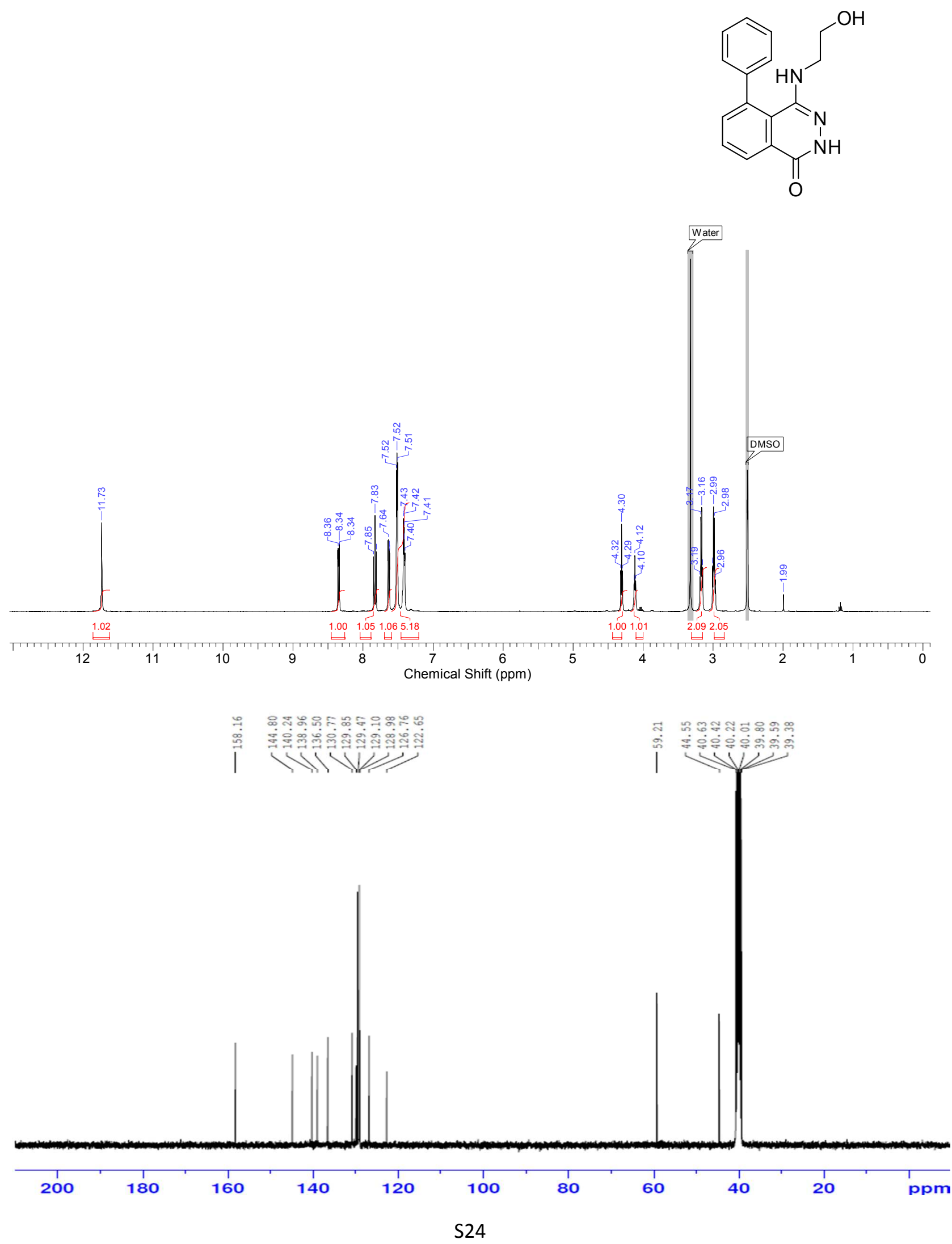

